Revista Brasil. Bot., V.32, n.1, p.117-129, jan.-mar. 2009

\title{
Morfoanatomia e ontogênese do pericarpo de Manihot caerulescens Pohl e M. tripartita Müll. Arg. (Euphorbiaceae) ${ }^{1}$
}

\author{
JONATHAS HENRIQUE GEORG DE OLIVEIRA² e DENISE MARIA TROMBERT OLIVEIRA ${ }^{3,4}$
}

(recebido: 03 de maio de 2007; aceito: 11 de dezembro de 2008)

\begin{abstract}
Morphology, anatomy and ontogeny of the pericarp of Manihot caerulescens Pohl and M. tripartita Müll. Arg. (Euphorbiaceae)). Manihot caerulescens and M. tripartita are shrub species of cerrado, known as "mandioca-brava". Works on structure of pericarp of Euphorbiaceae are rare and many of the found morphologic descriptions present dubious interpretations, especially on the dehiscence. The present work aimed to describe the morphology, anatomy and ontogeny of pericarp of the two species of Manihot, comparing themselves and relating structural aspects of pericarp to the dehiscence. We verified that the pericarp follow four developmental periods, as typical of dry fruits. Two meristems are formed: a subadaxial, that produces the inner mesocarp; and another adaxial, that forms the endocarp, homogeneous and collenchymatous in $M$. caerulescens, and heterogeneous in $M$. tripartita, with outer gelatinous fiber-sclereids and an collenchymatous inner portion. We observed the formation of separation tissue, composed of loose parenchyma, in direction to the dorsal bundle of the three carpels and to the septa, which are more evident in M. tripartita. Finally, we verified variation in the sclerenchymatous stratum: in M. caerulescens, there is a layer of fiber-sclereids and one of stone cells, both of the mesocarp; in M. tripartita, these two mesocarpic layers occur, with bigger thickness, increased of the outer endocarp, also composed of fiber-sclereids. The fruits of both species are capsules which type depends on the development of separation tissue and of the dimension of sclerenchymatous stratum. Thus $M$. caerulescens presents indehiscent capsules, while $M$. tripartita forms septi-loculicidal capsules, since the dehiscence, even so passive, occurs in the dorsal regions and in the direction to septa.
\end{abstract}

Key words - anatomy, development, Manihot, morphology, pericarp

RESUMO - (Morfoanatomia e ontogênese do pericarpo de Manihot caerulescens Pohl e M. tripartita Müll. Arg. (Euphorbiaceae)). Manihot caerulescens e M. tripartita são espécies arbustivas de cerrado, conhecidas como mandiocabrava. Não são encontrados muitos trabalhos sobre estrutura do pericarpo de Euphorbiaceae e muitas das descrições morfológicas existentes apresentam interpretações dúbias, especialmente sobre a deiscência. O presente trabalho objetivou descrever a morfologia, anatomia e ontogênese do pericarpo das duas espécies de Manihot, comparando-as entre si e relacionando aspectos estruturais do pericarpo à deiscência. Verificou-se que o desenvolvimento do pericarpo enquadra-se em quatro estágios, típicos de frutos secos. Dois meristemas são formados: um subadaxial, que produz o mesocarpo interno; outro adaxial, que forma o endocarpo, homogêneo e colenquimatoso em M. caerulescens, e heterogêneo em M. tripartita, com fibroesclereídes gelatinosas externas e uma porção colenquimatosa interna. Observou-se a formação de tecido de separação, composto por parênquima laxo, em direção aos feixes dorsais dos três carpelos e aos septos, o qual é mais evidente em $M$. tripartita. Por fim, verificou-se variação na composição do estrato esclerenquimático: em $M$. caerulescens, há uma faixa de fibroesclereídes e uma de braquiesclereídes, ambas do mesocarpo; em M. tripartita, ocorrem essas duas faixas mesocárpicas, com maior espessura, acrescidas do endocarpo externo, também composto por fibroesclereídes. Os frutos de ambas as espécies são cápsulas, cujo tipo varia em função do desenvolvimento do tecido de separação e da amplitude do estrato esclerenquimático. Assim, M. caerulescens apresenta cápsulas indeiscentes, enquanto $M$. tripartita forma cápsulas septiloculicidas, uma vez que a deiscência, embora passiva, ocorre nas regiões dorsais e em direção aos septos.

Palavras-chave - anatomia, desenvolvimento, Manihot, morfologia, pericarpo

1. Parte da dissertação de mestrado do primeiro autor, Programa de Pós-graduação em Ciências Biológicas (Botânica), Universidade Estadual Paulista, Botucatu, SP, Brasil.

2. UNESP - Universidade Estadual Paulista, Instituto de Biociências, Departamento de Botânica, Caixa Postal 510, 18618-000 Botucatu, SP, Brasil.

3. Universidade Federal de Minas Gerais, Instituto de Ciências Biológicas, Departamento de Botânica, Av. Antônio Carlos, 6627, Pampulha, Caixa Postal 486, 31270-901 Belo Horizonte, MG, Brasil.

4. Autor para correspondência: dmtoliveira@icb.ufmg.br

\section{Introdução}

Euphorbiaceae compreende aproximadamente 290 gêneros e 7.500 espécies distribuídas por todo o mundo, principalmente nas regiões tropicais e subtropicais (Barroso et al. 1991). Destes, cerca de 70 gêneros e 1.000 espécies são encontradas no Brasil (Barroso et al. 1991, Souza \& Lorenzi 2005). De acordo com Webster (1994), são reconhecidas cinco subfamílias, 
Phyllanthoideae, Oldfieldioideae, Acalyphoideae, Crotonoideae e Euphorbioideae, sendo que as duas primeiras apresentam dois óvulos por lóculo e as três outras um único óvulo por lóculo.

De acordo com APG (2003), Euphorbiaceae está inserida na ordem Malpighiales e é representada por indivíduos que apresentam somente um óvulo por lóculo; com isso, Phyllanthoideae foi reorganizada em Phyllanthaceae e Oldfieldioideae em Picrodendraceae.

A análise da literatura disponível revela que informações sobre anatomia de órgãos reprodutivos de Euphorbiaceae são escassas, destacando-se os trabalhos de Graner (1942), Landes (1946), Singh (1954, 1969), Toledo (1963), Singh \& Chopra (1970), Berg (1975), Lagôa \& Pereira (1989), Paoli et al. (1995) e Tokuoka \& Tobe $(1998,2002,2003)$. A carência de análises estruturais dos frutos destaca importante lacuna no conhecimento, especialmente quando se considera que as Euphorbiaceae podem formar vários tipos de frutos, como os esquizocarpáceos, capsulídeos, drupóides, bacóides e, mais raramente, cápsulas indeiscentes (Barroso et al. 1999). Além disso, muitas das descrições existentes estão fundamentadas apenas em observações morfológicas, as quais produzem, muitas vezes, interpretações dúbias que não se sustentam à luz de análises anatômicas e ontogenéticas.

Para o presente trabalho, selecionou-se $M$. caerulescens Pohl. e M. tripartita Müll. Arg. (Euphorbiaceae, Crotonoideae) ambas conhecidas popularmente como mandioca-brava; são espécies que ocorrem em fisionomias campestres de cerrado, cerrado típico e, eventualmente, em cerradão no estado de São Paulo (Durigan et al. 2004). Segundo registros da literatura, os frutos de $M$. caerulescens e $M$. tripartita apresentam deiscência do tipo loculicida e/ou septicida (Rogers \& Appan 1973). Vale ressaltar, contudo, que os autores não promoveram estudos anatômicos ou ontogenéticos que permitissem afirmar, com segurança, o tipo de deiscência que ocorre nestes frutos.

Estudos sobre a anatomia e a morfologia dos frutos são necessários devido à importância destas estruturas no ciclo de vida do vegetal. Diversas são as finalidades dos estudos estruturais como: verificar possíveis padrões morfológicos e anatômicos comuns entre táxons; indicar prováveis formas de especialização nos órgãos analisados; promover correta interpretação e classificação dos mesmos; e inclusive, fornecer bases seguras para solucionar problemas na identificação de determinadas espécies.

Tendo em vista estas considerações, este trabalho foi realizado com os seguintes objetivos: descrever a morfologia e anatomia do pericarpo de $M$. caerulescens e M. tripartita, nas diversas fases de seu desenvolvimento; identificar e relacionar as estruturas do fruto que compõem o diásporo, avaliando a ocorrência de deiscência; verificar possíveis padrões estruturais comuns às espécies estudadas e a outras Euphorbiaceae.

\section{Material e métodos}

O material botânico estudado constou de botões florais, flores e frutos nos vários estágios de desenvolvimento, coletados de indivíduos de Manihot caerulescens Pohl e M. tripartita Müll. Arg., localizados na Rodovia Geraldo Pereira de Barros nos km 167 e 170, próximo ao município de Botucatu, SP. Ramos férteis foram depositados no Herbário "Irina D. Gemtchujnicov" (BOTU) do Departamento de Botânica, UNESP, Câmpus de Botucatu, registrados respectivamente sob os números 25.202 e 20.090. O florescimento de $M$. caerulescens e $M$. tripartita ocorre a partir de setembro e os primeiros frutos são encontrados já em outubro.

O material coletado foi separado por tamanho, fixado em FAA em etanol 50\% (Johansen 1940) por 48 horas, com passagem em bomba de vácuo, seguindo-se a conservação em álcool etílico 70\% (Jensen 1962). Posteriormente, parte do material botânico foi desidratado em série etílica, incluído em metacrilato Leica ${ }^{\circledR}$ (de acordo com as instruções do fabricante) e seccionado em micrótomo de rotação em séries transversais e longitudinais; os cortes variaram entre 7 e $12 \mu \mathrm{m}$ de espessura e foram corados com azul de toluidina 0,05\% em pH 4,7 (O’Brien et al. 1964) e montados entre lâmina e lamínula com Entellan ${ }^{\circledR}$.

A região esclerenquimática dos frutos foi submetida à técnica de maceração de Franklin (1945), modificada conforme sugerido por Kraus \& Arduin (1997), montando-se em gelatina glicerinada (Dop \& Gautié 1928).

Também foram realizados testes para evidenciar algumas substâncias. Utilizaram-se os seguintes reagentes: floroglucinol com adição de ácido clorídrico concentrado, para evidenciar paredes lignificadas (Sass 1951); Sudan IV, para a localização de substâncias lipídicas; lugol, para a detecção de amido; e cloreto férrico, para verificar a ocorrência de compostos fenólicos (Johansen 1940).

Para a descrição dos resultados, utilizou-se a terminologia de Roth (1977) e de Barroso et al. (1999). A descrição do desenvolvimento foi feita em quatro estágios: estágio I - ovário; estágio II - frutos muito jovens, com divisões celulares por todo pericarpo; estágio III - frutos jovens em fase de alongamento e início da diferenciação celular; estágio IV - frutos maduros, com lignificação do estrato esclerenquimático.

Após a análise do laminário em microscópio de luz, os resultados foram documentados por meio de fotografias e fotomicrografias, sendo as escalas preparadas de modo convencional. As dimensões de 50 frutos maduros foram mensuradas com paquímetro, sendo apresentados os valores médios. 


\section{Resultados}

Estágio I - As flores estaminadas e pistiladas são encerradas somente pelas sépalas. As flores pistiladas (figura 1) são tricarpelares.

O ovário de $M$. caerulescens é trilocular e, em secção transversal, apresenta contorno hexagonal (figura 2) devido ao início da formação de seis projeções longitudinais (três dorsais e três em direção aos septos). Manihot tripartita tem ovário trilocular que tem secção transversal que tende a ser mais circular (figura 3).

A epiderme externa da parede ovariana de ambas as espécies é unisseriada, cuticularizada e estomatífera; algumas células apresentam conteúdo fenólico (figuras 4-5). Em M. tripartita, existem tricomas tectores unicelulares distribuídos, em grande quantidade, por toda a epiderme externa (figura 3); estes tricomas são alongados, possuem ápice afilado e parede espessada (figura 5), observando-se citoplasma pouco denso e núcleo evidente. Nas duas espécies, as células epidérmicas são cubóides, de citoplasma denso e apresentam núcleos centrais.

O mesofilo é parenquimático e apresenta, subabaxialmente, até três camadas de células com freqüentes idioblastos fenólicos. As demais células do mesofilo aumentam de tamanho em direção à região mediana, a partir de onde diminuem novamente (figura 4); por vezes, as células mais internas do mesofilo podem ser ainda menores que as externas. Cerca de quatro estratos celulares da região mais interna do mesofilo ovariano possuem células alongadas oblíqua e tangencialmente. Cordões procambiais estão imersos na região mediana do mesofilo (figura 4), com alguns elementos vasculares já diferenciados. Para cada carpelo, existem aproximadamente seis cordões procambiais laterais em $M$. caerulescens e oito em $M$. tripartita.

Os feixes vasculares dorsais já estão bem diferenciados neste estágio; são feixes colaterais, acompanhados por alguns idioblastos com substâncias fenólicas. Ocorrem seis feixes ventrais, dois por carpelo, sendo os feixes de carpelos adjacentes separados por tecido parenquimático com idioblastos fenólicos (figuras 6-7).

A epiderme interna da parede ovariana das duas espécies apresenta uma única camada de células cubóides (figuras 4, 8) com núcleos volumosos e centrais, glabra e delgadamente cuticularizada. São encontradas poucas células com conteúdo fenólico e, ainda na antese, observam-se algumas divisões periclinais (figura 8).

Estágio II - Quando jovens, os frutos são verdes e ocorre intensa atividade mitótica; em $M$. caerulescens destaca- se a ampliação das seis projeções longitudinais no fruto, três delas provenientes das regiões dorsais e outras três derivadas das regiões dos septos dos três carpelos. Durante o desenvolvimento do fruto, as sépalas secam e entram em abscisão.

O exocarpo é muito semelhante à epiderme externa da parede ovariana, porém evidenciam-se divisões anticlinais (figura 9).

O mesocarpo é multiplicativo, ocorrendo numerosas divisões nos planos periclinal, anticlinal e oblíquo. As divisões periclinais que ocorrem sob o exocarpo compõem o mesocarpo externo, região que abrange numerosas células com conteúdo fenólico (figura 9).

Nas duas espécies, o mesocarpo mediano apresenta células mais volumosas e divisões nos diversos planos. Diferenciam-se feixes vasculares na região lateral do pericarpo e ao longo dos septos. Os feixes dorsais são bem desenvolvidos e colaterais, inseridos próximo ao mesocarpo interno (figura 10). Neste estágio, observa-se a diferenciação de numerosos laticíferos de pequeno diâmetro, associados ou não aos feixes vasculares.

As camadas mais internas do mesocarpo mediano mostram células nitidamente alongadas nos sentidos tangencial e oblíquo, as quais são contínuas ao longo dos septos. O mesocarpo interno é constituído por um meristema subadaxial que apresenta células isodiamétricas, com citoplasma de conteúdo mais denso e núcleos bem volumosos (figuras 11-12).

O endocarpo de ambas as espécies é constituído pelo meristema adaxial que, desde muito jovem, apresenta divisões periclinais (figuras 11-12).

Na região axial, muitas células acumulam compostos fenólicos. Com o desenvolvimento do fruto, há instalação de câmbio nos feixes ventrais de carpelos adjacentes e também entre eles, fazendo com que, a partir de pequena atividade cambial, a vascularização ventral passe a ser constituída por três unidades, uma em direção a cada septo (figuras 13-14). Nos septos, numerosas divisões produzem o tecido de separação, composto por células cubóides e idioblastos fenólicos.

Estágio III - Os frutos crescem bastante (figuras 15-16), atingindo seu tamanho definitivo ao final deste estágio.

Com o desenvolvimento do fruto, o exocarpo passa por alterações, mantendo-se unisseriado (figuras 17-18). Suas paredes, porém, tornam-se mais espessadas, de natureza pecto-celulósica e a cutícula fica bem espessa (figura 19). Em M. tripartita, ainda podem ser observados os tricomas tectores, contudo, em menor densidade que no ovário (figura 17). Nesta espécie, forma-se uma pequena reentrância no exocarpo, acompanhada pelas 


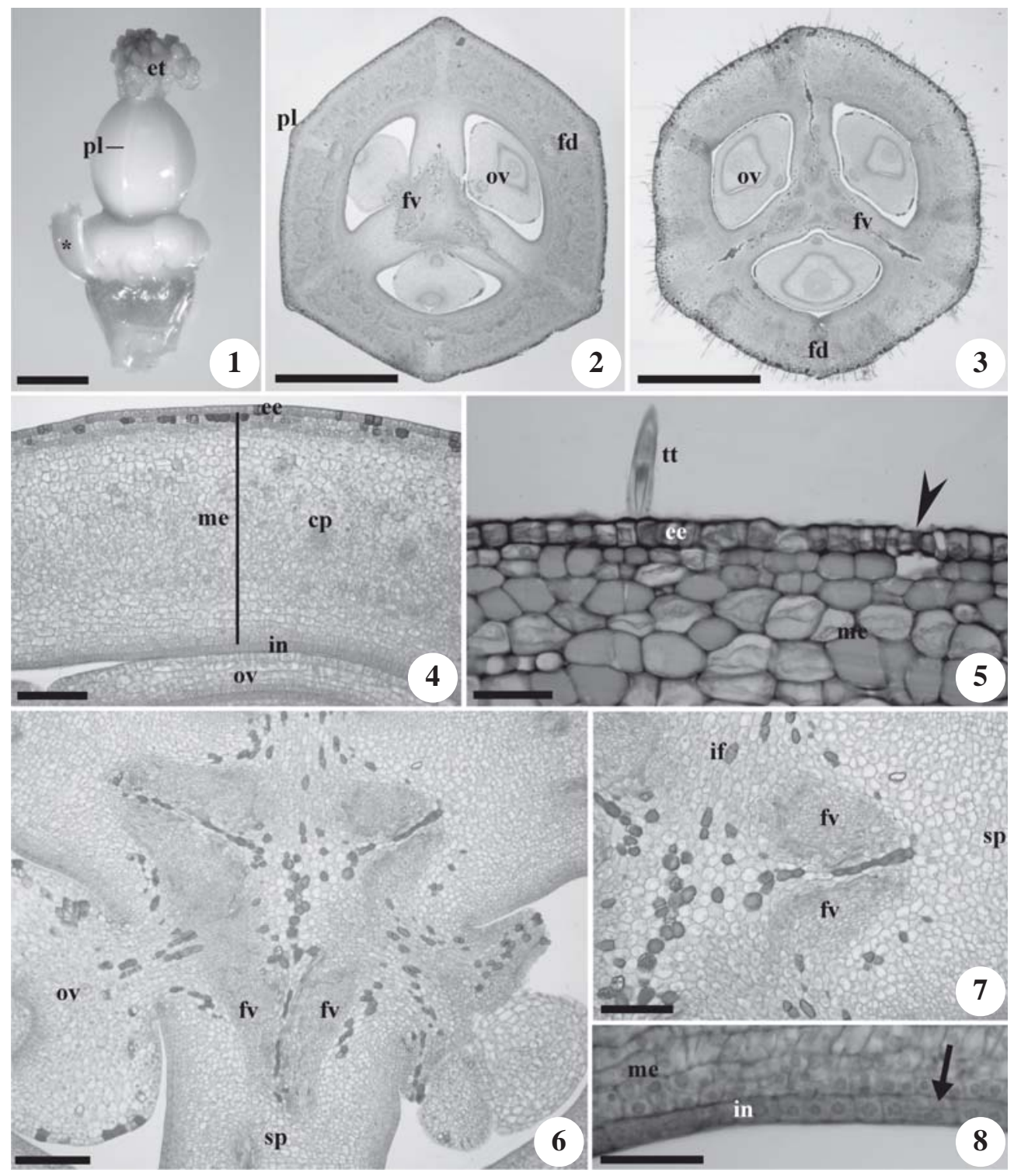

Figuras 1-8. Estágio I. Gineceu de Manihot caerulescens (1-2, 4, 6-8) e Manihot tripartita (3, 5). Secções transversais. 1. Aspecto geral do gineceu, após remoção das sépalas de flor pistilada (asterisco = base de uma sépala). 2-3. Vista geral do ovário, evidenciando o contorno mais anguloso e tendendo a circular respectivamente. 4. Aspecto geral da parede ovariana. 5. Detalhe da epiderme externa e de parte do mesofilo, destacando tricoma tector unicelular e estômato (ponta de seta). 6. Vista geral da região axial, mostrando os seis feixes ventrais. 7. Detalhe da figura anterior, destacando os dois feixes ventrais de carpelos adjacentes. 8. Porção interna do mesofilo e epiderme interna unisseriada, mostrando as primeiras divisões periclinais (seta). $(\mathrm{cp}=$ cordão procambial; $\mathrm{ee}=$ epiderme externa; et = estigma; $\mathrm{fd}=$ feixe dorsal; $\mathrm{fv}=$ feixe ventral; if $=$ idioblasto fenólico; in = epiderme interna; $\mathrm{me}=$ mesofilo; $\mathrm{ov}=$ óvulo; $\mathrm{pl}=$ projeção lateral; $\mathrm{sp}=$ septo; $\mathrm{tt}=$ tricoma tector ). Barra $=2 \mathrm{~mm}(1-3), 100 \mu \mathrm{m}(4,7), 50 \mu \mathrm{m}(5,8), 150 \mu \mathrm{m}(6)$.

Figures 1-8. Stage I. Gynoecium of Manihot caerulescens (1-2, 4, 6-8) and Manihot tripartita (3, 5). Transverse section. 1. General aspect of gynoecium, after remove sepals from pistillate flower (asterisk = base of one sepal). 2-3. General view, evidencing the contour most angulate and tending to round, respectively. 4. General aspect of the ovary wall. 5. Detail of the outer epidermis and part of the mesophyll, detaching unicellular non-glandular trichome and stoma (arrowhead). 6. General view of the axile region, showing six ventral bundles. 7. Detail of the previous figure, detaching two ventral bundles of adjacent carpels. 8. Inner portion of the mesophyll and uniseriate inner epidermis, showing the first periclinal divisions (arrow). $(\mathrm{cp}=$ procambial strand; ee $=$ outer epidermis; et $=$ stigma; $\mathrm{fd}=$ dorsal bundle; $\mathrm{fv}=$ ventral bundle; if $=$ phenolic idioblast; in = inner epidermis; $\mathrm{me}=$ mesophyll; ov = ovule; $\mathrm{pl}=$ lateral projection; $\mathrm{sp}=$ septum; $\mathrm{tt}=$ non-glandular trichome). Bar $=2 \mathrm{~mm}(1-3), 100 \mu \mathrm{m}(4,7), 50 \mu \mathrm{m}(5,8), 150 \mu \mathrm{m}(6)$. 


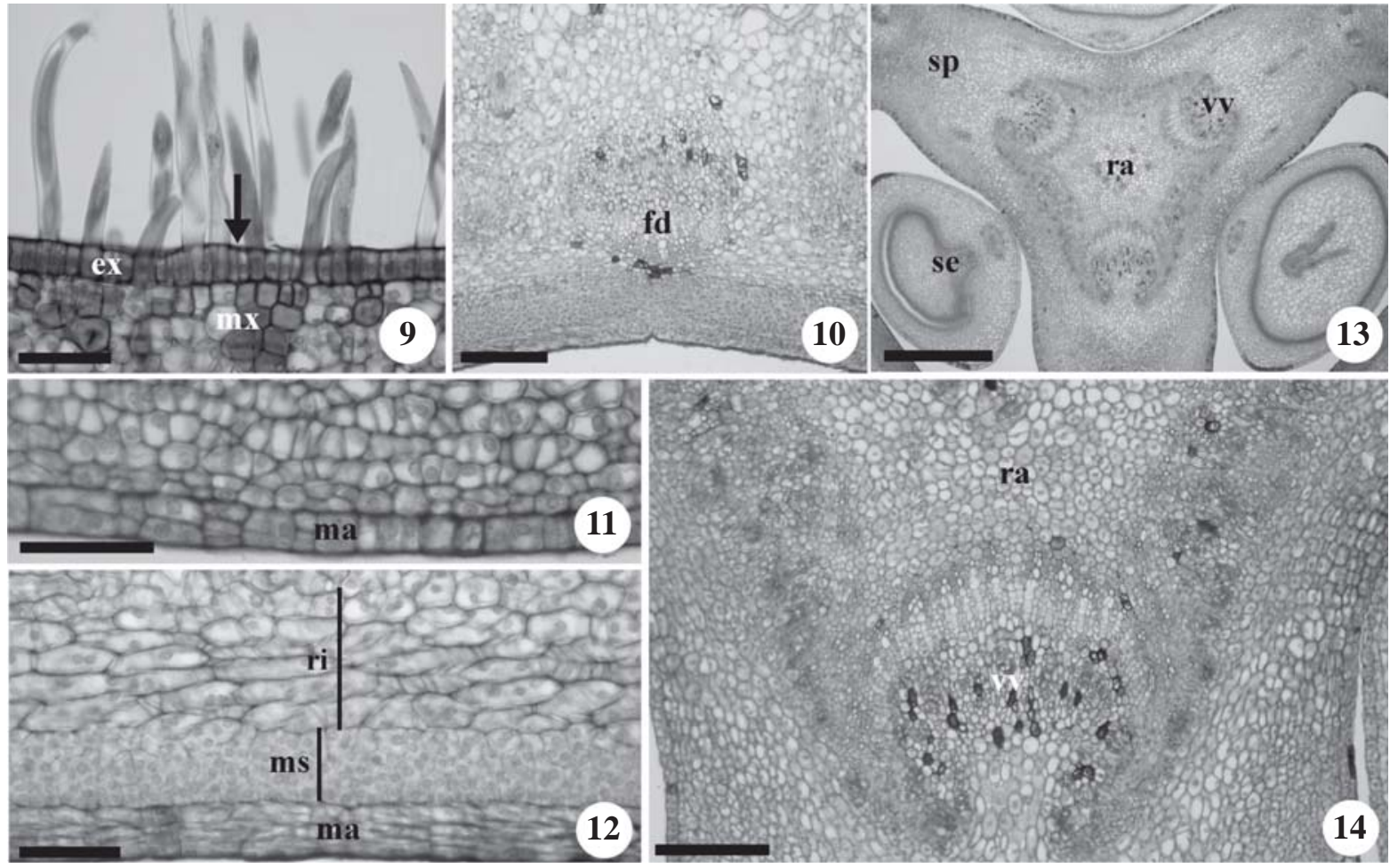

Figuras 9-14. Estágio II. Início de desenvolvimento do fruto de Manihot caerulescens (11-12) e Manihot tripartita (9-10, 13-14). Secções longitudinais (9,11-12). Secções transversais (10,13-14). 9. Detalhe do exocarpo, evidenciando tricomas tectores unicelulares (seta $=$ divisões anticlinais), e do mesocarpo externo. 10. Aspecto da região dorsal, evidenciando amplo feixe. 11. Detalhe da porção interna do pericarpo jovem, mostrando o meristema adaxial com numerosas divisões periclinais. 12. Detalhe da região interna do mesocarpo mediano e do mesocarpo interno, o qual constitui o meristema subadaxial. 13. Vista da região axial, mostrando as três unidades vasculares ventrais, resultantes da união de feixes feita pelo câmbio entre carpelos adjacentes. 14. Detalhe da figura anterior. (ex = exocarpo; $\mathrm{fd}=$ feixe dorsal; $\mathrm{ma}=$ meristema adaxial; $\mathrm{ms}=$ meristema subadaxial $; \mathrm{mx}=$ mesocarpo externo; $\mathrm{ra}=$ região axial; $\mathrm{ri}=$ região mais interna do mesocarpo mediano; $\mathrm{se}=$ semente; $\mathrm{sp}=$ septo; vv = vascularização ventral). Barra $=500 \mu \mathrm{m}(13), 150 \mu \mathrm{m}(10,14), 50 \mu \mathrm{m}(9,11-12)$.

Figures 9-14. Stage II. Beginning of the fruit development of Manihot caerulescens (11-12) and Manihot tripartita (9-10, 13-14). Longitudinal section (9, 11-12). Transverse section (10, 13-14). 9. Detail of exocarp, evidencing unicellular non-glandular trichomes (arrow $=$ anticlinal divisions), and of the outer mesocarp. 10. Aspect of the dorsal region, evidencing large bundle. 11. Detail of the inner portion of the young pericarp, showing the adaxial meristem with numerous periclinal divisions. 12. Detail of the inner region of the medium mesocarp, and inner mesocarp, which constitutes the subadaxial meristem. 13. View of the axile region, showing the three units of ventral vasculature, resultant of the bundle union by the cambium between adjacent carpels. 14 . Detail of the previous figure. $(\mathrm{ex}=$ exocarp; $\mathrm{fd}=$ dorsal bundle; $\mathrm{ma}=$ adaxial meristem; $\mathrm{ms}=$ subadaxial meristem; $\mathrm{mx}=$ outer mesocarp; $\mathrm{ra}=$ axile region; $\mathrm{ri}=$ innermost region of the medium mesocarp; se $=$ seed; $\mathrm{sp}=$ septum; $\mathrm{vv}=$ ventral vasculature $).$ Bar $=500 \mu \mathrm{m}(13), 150 \mu \mathrm{m}(10,14), 50 \mu \mathrm{m}(9,11-12)$.

camadas mais externas do mesocarpo, localizada sobre o tecido de separação de cada região dorsal (figura 18).

É no mesocarpo que ocorrem as principais alterações relativas à estrutura do fruto. Na fase de diferenciação, as células mesocárpicas aumentam muito de volume, fazendo com que o fruto cresça consideravelmente. A quantidade de células que armazenam substâncias fenólicas também aumenta muito, principalmente no mesocarpo externo que passa a ter, em $M$. caerulescens, até dez camadas destas células, contra cerca de seis em M. tripartita.

No mesocarpo mediano ocorre, ainda, aumento no número de camadas de células e no volume das mesmas. Há também grande diferenciação dos feixes vasculares laterais, que são anficrivais (figura 20).

A quantidade de laticíferos também aumenta muito, em $M$. caerulescens visivelmente mais que em $M$. tripartita; os laticíferos encontram-se mais diferenciados, 


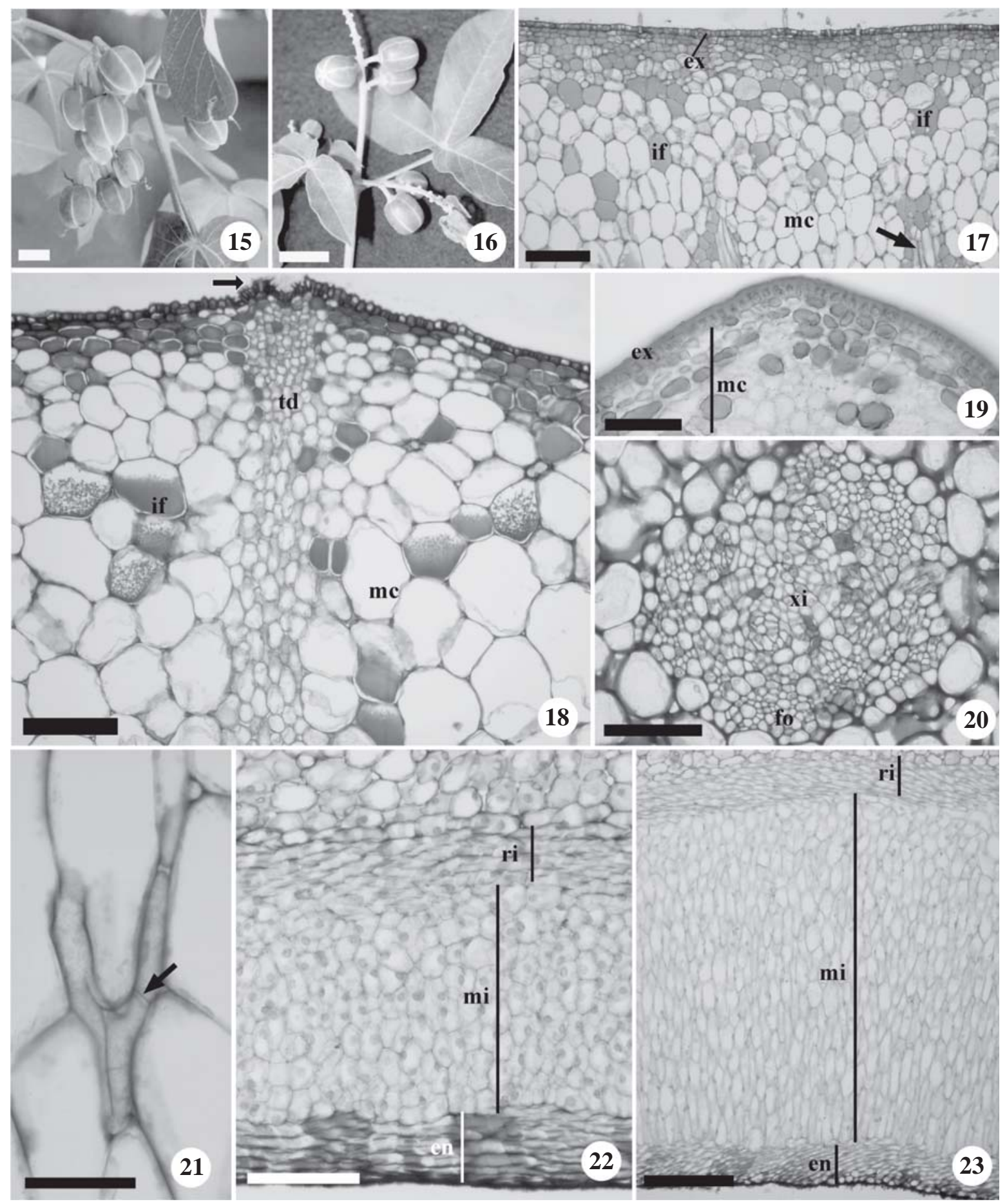

Figuras 15-23. Estágio III. Fruto de Manihot caerulescens (15, 19-20) e Manihot tripartita (16-18, 21-23). Secção longitudinal (17). Secções transversais (18-23). 15-16. Ramos com frutos jovens. 17. Aspecto do exocarpo unisseriado e mesocarpo jovem, com evidente acúmulo de células fenólicas; notar células intensamente alongadas inseridas no mesocarpo (seta). 18. Detalhe da região dorsal, destacando o tecido de separação; notar pequena reentrância encontrada no exocarpo e camadas externas do mesocarpo na região dorsal (seta). 19. Aspecto do pericarpo, evidenciando a cutícula espessa no exocarpo. 20. Detalhe de feixe lateral do tipo anficrival. 21. Detalhe do laticífero articulado e ramificado (seta = articulação). 22-23. Detalhe da região interna do mesocarpo mediano, do mesocarpo interno e do endocarpo com vários estratos celulares, respectivamente no início e no final deste estágio. (en = endocarpo; ex = exocarpo; if = idioblasto fenólico; fo = floema; $\mathrm{mc}=$ mesocarpo; $\mathrm{mi}=$ mesocarpo interno; $\mathrm{ri}=$ região mais interna do mesocarpo mediano; $\mathrm{td}=$ tecido de separação na região dorsal; $x i=$ xilema). Barra $=15 \mathrm{~mm}(15-16), 150 \mu \mathrm{m}(17-18,23), 100 \mu \mathrm{m}(19-20,22), 50 \mu \mathrm{m}(21)$. 
sendo articulados e ramificados (figura 21); estão dispersos por todo o mesocarpo externo e mediano, bem como associados aos feixes vasculares.

As células da região mais interna do mesocarpo mediano tornam-se mais oblíquas e alongadas tangencialmente (figuras 22, 23).

O mesocarpo interno amplia-se muito, principalmente em $M$. tripartita, em que estas células passam a apresentar alongamento radial (figura 23). Já em $M$. caerulescens, o crescimento não acontece de forma tão acentuada e suas células apresentam-se mais arredondadas (figura 22).

Já no início do estágio de diferenciação, o tecido de separação pode ser reconhecido pelas células menores e ligeiramente alongadas no sentido radial, tanto na região voltada para os feixes dorsais (figura 18) quanto para os septos.

No endocarpo de ambas as espécies, ocorrem camadas de células obliquamente posicionadas, levemente alongadas no sentido tangencial (figuras 22, 23).

Estágio IV - Os frutos maduros de M. caerulescens são indeiscentes e medem, em média, aproximadamente 3,2 $\mathrm{cm}$ de comprimento por $2,6 \mathrm{~cm}$ de diâmetro, enquanto que, em M. tripartita, os frutos são deiscentes e medem aproximadamente $1,8 \mathrm{~cm}$ de comprimento por $1,6 \mathrm{~cm}$ de diâmetro. Os frutos dessa última espécie são mais globosos, com tricomas dispersos e não visíveis a olho nu, enquanto os frutos de $M$. caerulescens são ovados e realmente glabros (figura 24).

No exocarpo de ambas as espécies, o tamanho das células fica reduzido e seu contorno mais irregular, em função do grande alongamento pericárpico; há também um acentuado aumento da cutícula, observado principalmente em $M$. caerulescens. Os tricomas permanecem esparsos no exocarpo de $M$. tripartita (figura 25).

No fruto bem desenvolvido, poucas camadas de células do mesocarpo externo apresentam paredes ligeiramente mais espessas e densamente fenólicas em $M$. tripartita; essa região pode atingir cerca de dez camadas celulares em $M$. caerulescens.

No mesocarpo mediano, ocorre aumento acentuado no volume das células, observando-se reserva amilácea na região mais interna em ambas as espécies. Vários grupos de fibras podem ser observados, espalhados pelo mesocarpo mediano exclusivamente em $M$. tripartita (figura 29), associados ou não a feixes vasculares.

Os laticíferos ocorrem por todo o mesocarpo, principalmente no mesocarpo mediano, associados ou não a feixes vasculares. Eles permanecem ativos na maturidade, apresentando nítido conteúdo lipídico; a fresco, o látex apresenta coloração amarelada.

Tanto em M. caerulescens quanto em M. tripartita, na direção dos feixes dorsais, observa-se a presença de camadas de células parenquimáticas menores que as contíguas (figuras 26,27), abrigando espaços intercelulares que são mais evidentes em M. caerulescens (figura 26). Nesta espécie, este tecido contrai-se na maturidade; em M. tripartita, atua como tecido de separação sobre o qual se dá a abertura dorsal. Já em direção aos septos, existe um tecido parenquimático amplo e coeso em $M$. caerulescens, sem grandes espaços intercelulares, o qual é contínuo com o parênquima do septo (figura 28) e também se contrai na maturidade; em $M$. tripartita, ocorre um tecido de separação semelhante ao dorsal e o parênquima do septo tem aspecto laxo (figura 29).

As células mais internas do mesocarpo mediano, alongadas tangencial e obliquamente, são diferenciadas em aproximadamente cinco camadas de fibroesclereídes gelatinosas em $M$. caerulescens (figura 30) e cerca de oito em $M$. tripartita (figura 31); são células não muito longas e de extremidades ligeiramente afiladas (figuras 33, 35), cujas paredes são lignificadas perifericamente, com nítida impregnação péctica na região interna da parede. Em M. tripartita, um pequeno grupo dessas células mostra-se contínuo mesmo em direção aos septos (figura 29).

Figures 15-23. Stage III. Fruit of Manihot caerulescens (15, 19-20) and Manihot tripartita (16-18, 21-23). Longitudinal section (17). Transverse section (18-23). 15-16. Branches with young fruits. 17. Aspect of the uniseriate exocarp and young mesocarp, with evident accumulation of phenolic cells; note cells intensely elongated, inserted in the mesocarp (arrow). 18. Detail of the dorsal region, detaching the separation tissue; note the small reentrance found in exocarp and outer layers of mesocarp in the dorsal region (arrow). 19. Aspect of pericarp, evidencing thick cuticle in exocarp. 20. Detail of the lateral amphicribral bundle. 21. Detail of the articulated-branched laticifer (arrow = end wall). 22-23. Detail of the inner region of the medium mesocarp, inner mesocarp and endocarp with some cellular layers, in the beginning and the end of this stage respectively. $(\mathrm{en}=$ endocarp; $\mathrm{ex}=$ exocarp; if $=$ phenolic idioblast; fo = phloem; $\mathrm{mc}=$ mesocarp; $\mathrm{mi}=$ inner mesocarp; $\mathrm{ri}=$ innermost region of the medium mesocarp; $t d=$ separation tissue in the dorsal region; $x i=x y l e m) . ~ B a r=15 \mathrm{~mm}(15-16)$, $150 \mu \mathrm{m}(17-18,23), 100 \mu \mathrm{m}(19-20,22), 50 \mu \mathrm{m}(21)$. 

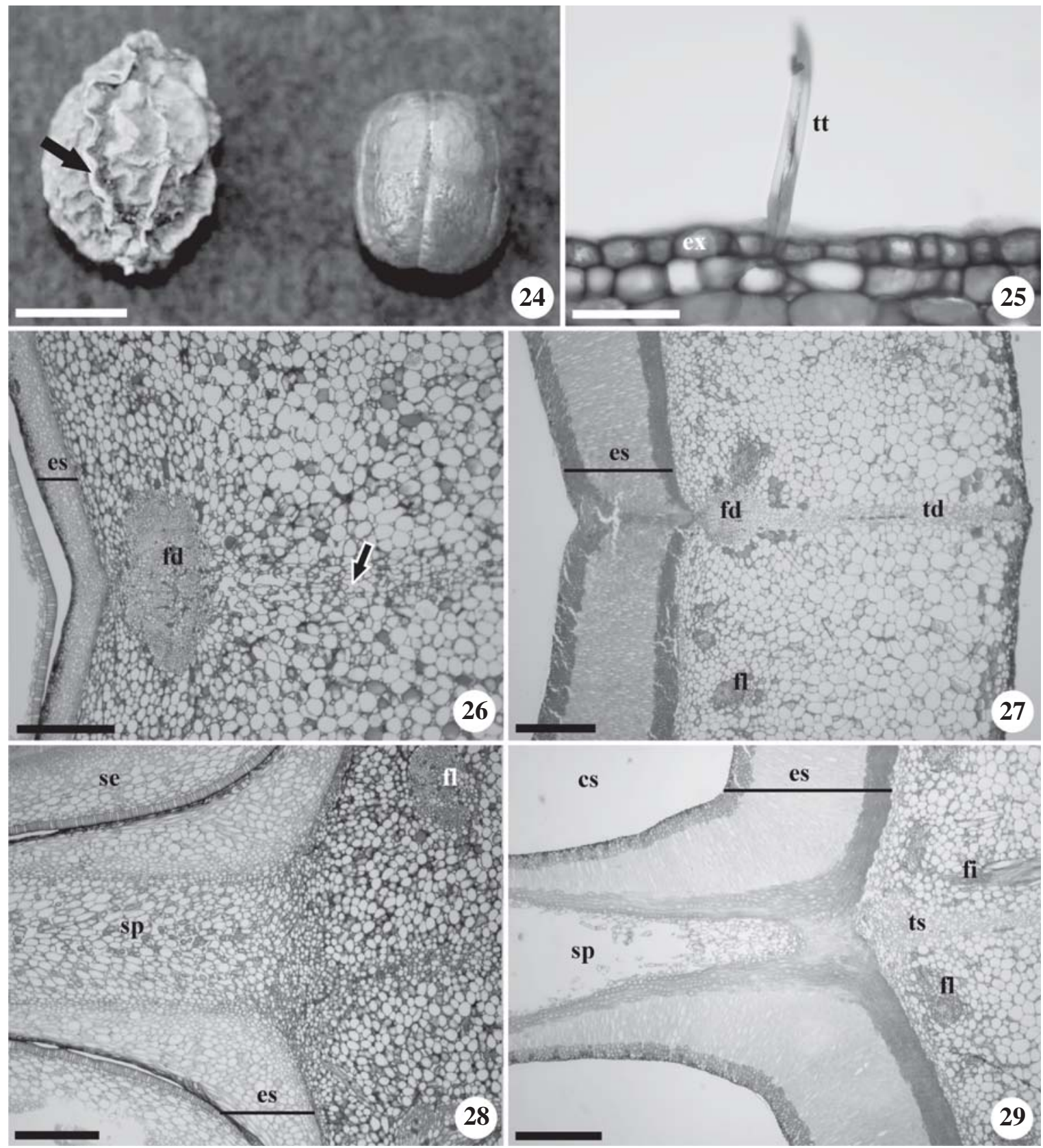

Figuras 24-29. Estágio IV. Fruto em maturação de Manihot caerulescens (24 à esquerda, 26, 28) e Manihot tripartita (24 à direita, 25, 27, 29). Secções transversais (25-29). 24. Frutos maduros (seta = projeção lateral). 25. Detalhe do exocarpo, evidenciando tricoma tector e cutícula espessa, e de parte do mesocarpo externo. 26. Região dorsal; notar tecido parenquimático mais frouxo em direção ao feixe dorsal (seta) e a pequena espessura do estrato esclerenquimático. 27. Região dorsal, destacando evidente tecido de separação e amplo estrato esclerenquimático. 28-29. Região do septo. (cs = cavidade seminal; es = estrato esclerenquimático; $\mathrm{ex}=$ exocarpo; $\mathrm{fd}=$ feixe dorsal; $\mathrm{fi}=$ fibras; $\mathrm{fl}=$ feixe lateral; $\mathrm{se}=$ semente; $\mathrm{sp}=$ septo; $\mathrm{td}=$ tecido de separação na região dorsal; ts = tecidos de separação; $t \mathrm{t}=$ tricoma tector). Barra $=1 \mathrm{~cm}(24), 500 \mu \mathrm{m}(26-29), 50 \mu \mathrm{m}(25)$.

Figures 24-29. Stage IV. Fruit in maturation of Manihot caerulescens (24 left, 26, 28) and Manihot tripartita (24 right, 25, 27, 29). Transverse section (25-29). 24. Mature fruits (arrow = lateral projection). 25. Detail of the exocarp, evidencing non-glandular trichome and thick cuticle, and part of the outer mesocarp. 26. Dorsal region; note loose parenchyma in direction to the dorsal bundle (arrow) and the small thickness of the sclerenchymatous stratum. 27. Dorsal region, detaching evident separation tissue and large sclerenchymatous stratum. 28-29. Region of the septum. (cs = seed chamber; es = sclerenchymatous stratum; ex = exocarp; $\mathrm{fd}=$ dorsal bundle; $\mathrm{fi}=$ fiber; $\mathrm{fl}=$ lateral bundle; $\mathrm{se}=\mathrm{seed} ; \mathrm{sp}=$ septum; $\mathrm{td}=$ separation tissue in the dorsal region; $\mathrm{ts}=$ separation tissue; $\mathrm{tt}=$ non-glandular trichome). $\mathrm{Bar}=1 \mathrm{~cm}(24), 500 \mu \mathrm{m}(26-29), 50 \mu \mathrm{m}(25)$. 
Um estrato de braquiesclereídes, que mantém citoplasma, vacúolos e núcleos evidentes até a maturidade, compõe o mesocarpo interno, com até nove camadas de células mais arredondadas em $M$. caerulescens (figuras

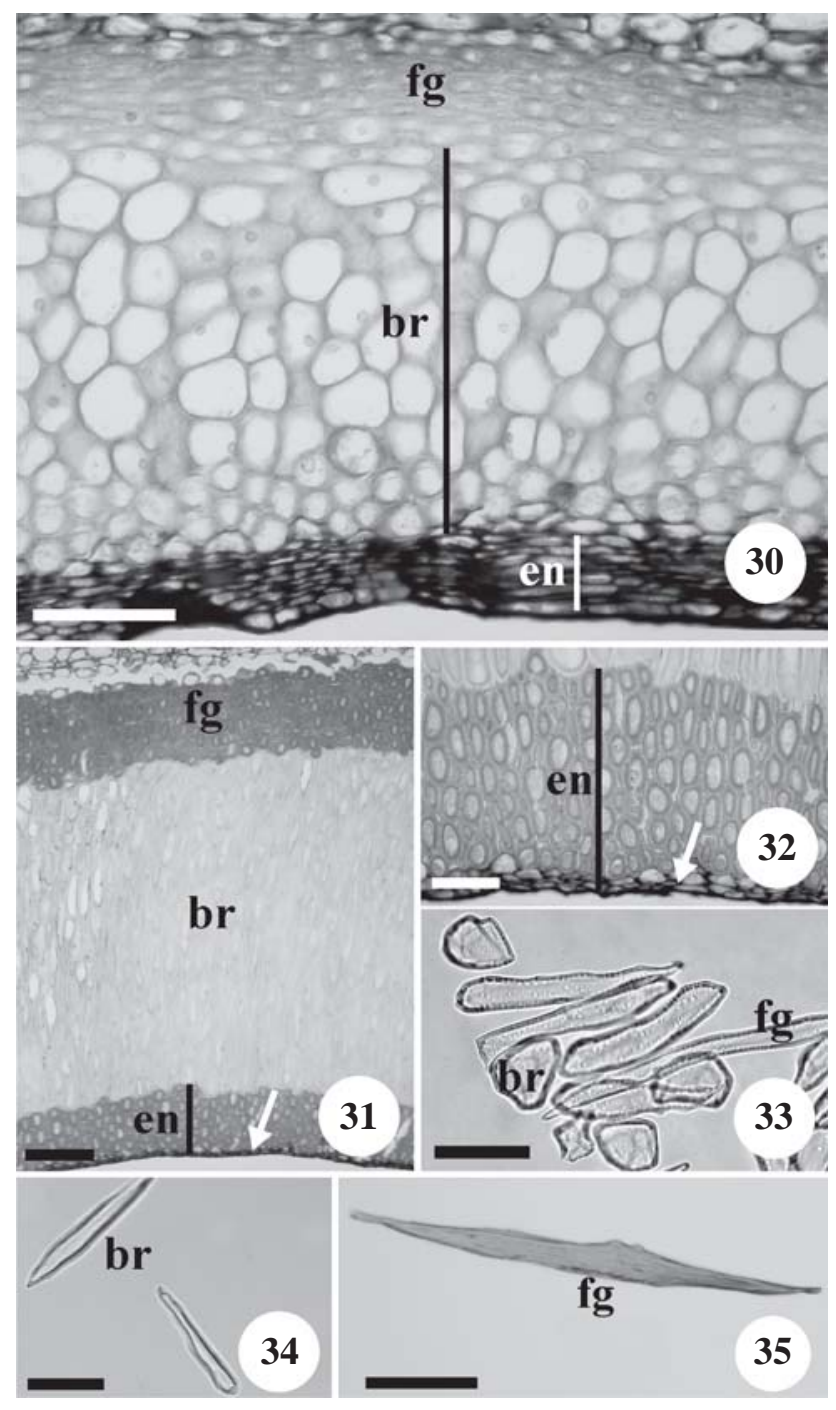

Figuras 30-35. Estágio IV. Fruto em maturação de Manihot caerulescens (30, 33) e Manihot tripartita (31, 32, 34, 35). Material dissociado (33-35). Secções transversais (30-32). 30. Detalhe do estrato esclerenquimático, composto por fibroesclereídes e braquiesclereídes mesocárpicas, acompanhado pelo endocarpo colenquimatoso. 31. Detalhe do estrato esclerenquimático, composto por fibroesclereídes e braquiesclereídes mesocárpicas e fibroesclereídes endocárpicas; notar a delgada região colenquimatosa mais interna (ponta de seta). 32. Detalhe das fibroesclereídes gelatinosas endocárpicas ( 33-35. Detalhe das células componentes do estrato esclerenquimático. (br = braquiesclereídes; en = endocarpo; $\mathrm{fg}=$ fibroesclereídes gelatinosas). Barra $=300 \mu \mathrm{m}(34)$, $150 \mu \mathrm{m}$ (31), $100 \mu \mathrm{m}$ (30, 33, 35), $50 \mu \mathrm{m}$ (32).
28, 30) e até dez camadas de braquiesclereídes com alongamento radial em $M$. tripartita (figuras 29, 31, 34).

Em $M$. caerulescens, o endocarpo do fruto maduro é exclusivamente de natureza colenquimatosa, com aproximadamente seis a oito camadas de células (figura 30), algumas das quais acumulam substâncias fenólicas. Já em M. tripartita, o endocarpo tem composição mista: as camadas mais externas encontram-se diferenciadas em aproximadamente oito estratos de fibroesclereídes gelatinosas e somente cerca de três camadas celulares mantêm-se colenquimatosas (figuras 31, 32).

Em resumo, ao final do desenvolvimento do pericarpo, observa-se a presença de lignificação na parte mais interna do mesocarpo mediano e no mesocarpo interno de $M$. caerulescens; em $M$. tripartita, estas mesmas regiões são lignificadas, o que também ocorre com a região mais externa do endocarpo.

Em M. caerulescens, ao fim do estágio de maturação, o pericarpo desidrata-se intensamente, ocorrendo retração do parênquima mesocárpico e enrugamento de toda a porção do pericarpo externa às camadas lignificadas. Mesmo no fruto maduro, encontra-se reserva de amido nas células que compõem o tecido de separação e na região axial, contornando a vascularização ventral (figura 36). Na maturidade das duas espécies, o câmbio mantém-se em atividade nas unidades ventrais, visualizando-se a nítida presença de xilema e floema secundários (figura 37) e a região axial com grandes espaços intercelulares (figuras 36, 38).

\section{Discussão}

A descrição do desenvolvimento dos frutos e sementes utilizando períodos de crescimento foi inicialmente feita por pesquisadores que analisaram pericarpos carnosos (Lilleland 1930, Tukey \& Young

Figures 30-35. Stage IV. Mature fruit of Manihot caerulescens (30, 33) and Manihot tripartita (31, 32, 34, 35). Dissociated material (33-35). Transverse section (30-32). 30. Detail of the sclerenchymatous stratum composed of mesocarpic fibersclereids and stone cells, accompanied by collenchymatous endocarp. 31. Detail of the sclerenchymatous stratum composed of mesocarpic fiber-sclereids and stone cells, and endocarpic fiber-sclereids; note the innermost thin collenchymatous region (arrow). 32. Detail of gelatinous fiber-sclereids of the endocarp (arrow = collenchymatous cells). 33-35. Detail of the sclerenchymatous stratum cells. (br = stone cell; $\mathrm{en}=$ endocarp; $\mathrm{fg}=$ gelatinous fiber-sclereid). Bar $=300 \mu \mathrm{m}$ (34), $150 \mu \mathrm{m}$ (31), $100 \mu \mathrm{m}(30,33,35)$, $50 \mu \mathrm{m}(32)$. 

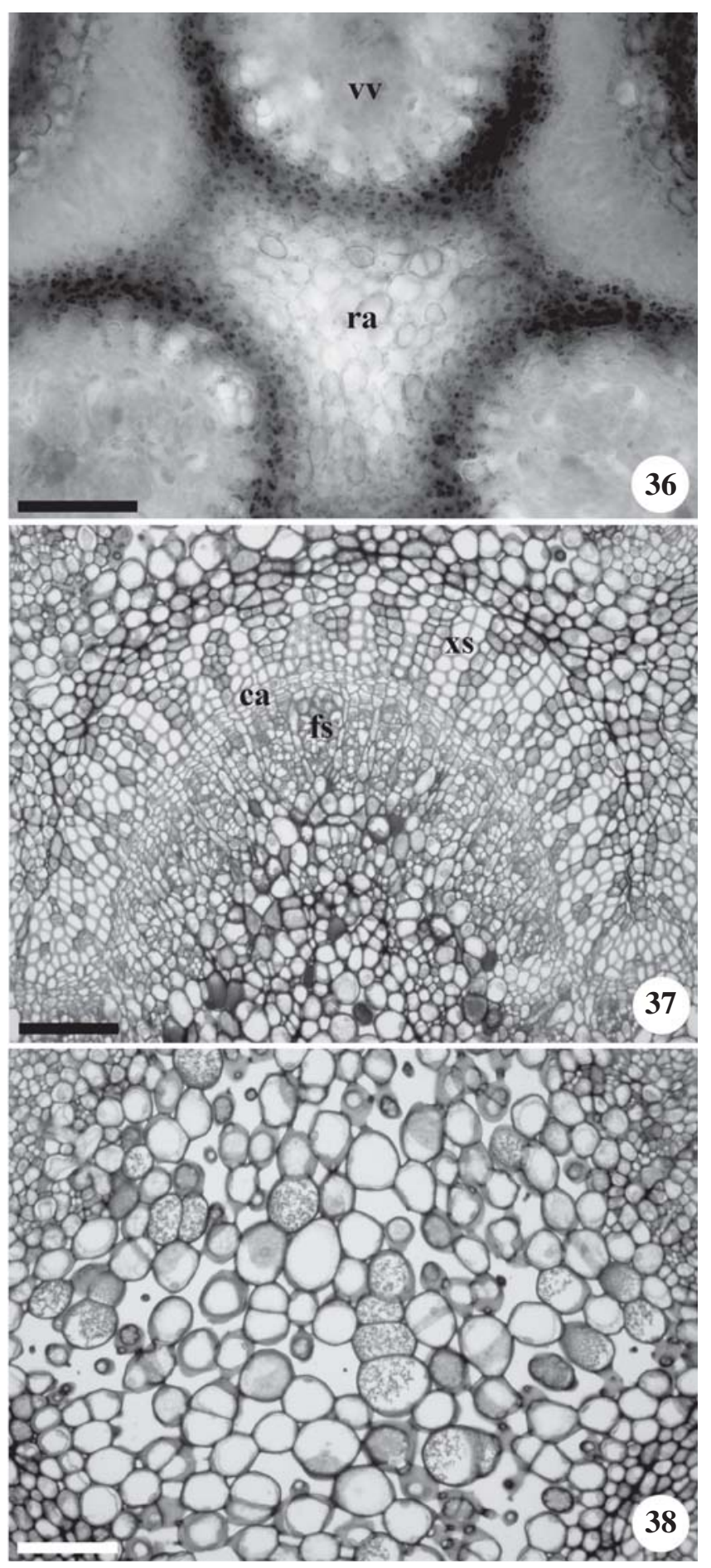

Figuras 36-38. Estágio IV. Região axial do fruto de Manihot caerulescens. Secções transversais. 36. Vista geral, evidenciando numerosos grãos de amido. 37. Detalhe do feixe ventral, mostrando a presença de câmbio e de xilema e floema secundários. 38. Detalhe do parênquima da região axial, destacando os nítidos espaços intercelulares. $(\mathrm{ca}=$ câmbio; fs = floema secundário; ra = região axial; vv = vascularização ventral; $\mathrm{xs}=$ xilema secundário). Barra $=$ $100 \mu \mathrm{m}$.
1939). Eles reconheceram três ciclos de crescimento: o primeiro, em que ocorre rápido aumento no tamanho do fruto e tegumentos seminais; o segundo, onde o embrião se diferencia, embora a velocidade de crescimento do fruto diminua sensivelmente; e o terceiro, que é caracterizado pela paralisação do desenvolvimento do embrião e retomada de ativo alongamento no fruto. Como tal procedimento mostrou-se eficiente, os frutos secos também passaram a ser descritos desta maneira, com algumas adaptações, principalmente porque, nesses pericarpos, o crescimento não é retomado após o desenvolvimento seminal (Souza 1984, Oliveira \& Beltrati 1993, Pietrobom \& Oliveira 2004).

O pericarpo das espécies estudadas apresentou o desenvolvimento característico dos frutos secos, partindo da estrutura ovariana (denominado de estágio I), passando pelo ciclo de crescimento por divisão celular (estágio II), seguido da fase de alongamento celular (estágio III) e, finalmente, apresentando a lignificação do estrato esclerenquimático pericárpico (estágio IV).

No ovário de ambas as espécies estudadas, observase a vascularização básica, ou seja, um feixe dorsal, dois feixes ventrais e alguns cordões procambiais laterais por carpelo. Durante o estágio II, ressalta-se a precoce diferenciação do câmbio entre os feixes ventrais adjacentes em cada septo, que culmina na produção das três grandes unidades vasculares ventrais, já compostas por tecidos secundários.

Sem dúvida alguma, um caráter que chama a atenção nas Euphorbiaceae é a presença de laticíferos. Esau (1959) e Cutter (1986) classificaram os laticíferos de Manihot como articulados não ramificados, do mesmo tipo que encontrado em Hevea, os quais se caracterizam por surgirem a partir de grupos de células enfileiradas, em que os protoplastos são fundidos após a dissociação completa ou incompleta das paredes limítrofes. A articulação foi encontrada nos laticíferos dos frutos de M. caerulescens e $M$. tripartita, os quais ocorrem em grande quantidade, dispersos pelo mesocarpo. Contudo, os laticíferos amostrados neste trabalho são ramificados em ambas as espécies, contrapondo a generalização de

Figures 36-38. Stage IV. Axile region of the fruit of Manihot caerulescens. Transverse sections. 36. General view, evidencing numerous starch grains. 37 . Detail of the ventral bundle, showing the presence of cambium and secondary xylem and phloem. 38. Detail of parenchyma of the axile region, detaching the conspicuous intercellular spaces. $(\mathrm{ca}=$ cambium; fs = secondary phloem; ra = axile region; $\mathrm{vv}=$ ventral vasculature; $\mathrm{xs}=$ secondary $\mathrm{xylem})$. $\mathrm{Bar}=100 \mu \mathrm{m}$. 
que os laticíferos de Manihot são articulados e não ramificados.

Quando frutos com porções internas lenhosas são avaliados, é comum referir-se ao endocarpo, sem levar em conta detalhes da ontogênese. A porção lenhosa dos frutos de várias espécies de Euphorbiaceae tem sido referida como endocarpo pela maioria dos autores, como Toledo (1963), em seu estudo ontogenético com fruto e semente de M. utilissima (mandioca). Berg (1975), analisando os órgãos reprodutivos de espécies de Micrantheum, também se refere à porção lenhosa do pericarpo como endocarpo. Por sua vez, Añes et al. (2005) também chamaram a porção lenhosa do fruto de Jatropha elliptica de endocarpo, porém partindo de análises morfológicas e não ontogenéticas, como os dois autores anteriores.

As espécies de Manihot aqui estudadas apresentam um meristema subadaxial, que desenvolve esclereídes no mesocarpo interno do fruto maduro. Dos vários autores consultados, apenas Berg (1975) refere-se à existência de tal região, encontrada já na parede ovariana de espécies de Micrantheum.

É provável que os autores que chamam toda a porção esclerenquimática dos frutos das Euphorbiaceae de endocarpo não apliquem o conceito ontogenético, explicitado por Roth (1977), segundo o qual a epiderme externa ovariana origina o exocarpo, o mesofilo da parede ovariana forma o mesocarpo e a epiderme interna diferencia-se no endocarpo. Aplicando-se este conceito ontogenético aos pericarpos de $M$. caerulescens e $M$. tripartita, verifica-se nitidamente a ampla participação do mesocarpo na formação do estrato esclerenquimático, podendo haver (em $M$. tripartita) ou não (em $M$. caerulescens) a participação de células endocárpicas.

Toledo (1963), analisando os frutos de M. utilissima, relatou que há um tecido que forra a cavidade da semente, o qual chamou de "epiderme interna do ovário". A referência a uma camada ovariana no interior do fruto é inadequada, visto que é exatamente esta epiderme que forma o endocarpo. Analisando-se os resultados de Toledo (1963) e comparando-os com os aqui obtidos, pode-se afirmar que o tecido ao qual a autora se refere são as camadas colenquimatosas do endocarpo.

Vários autores, dentre os quais Toledo (1963), Roosmalen (1985) e Webster (1994), classificaram os frutos de Manihot apenas como cápsulas, não caracterizando sua deiscência. Segundo o afirmado por Rogers \& Appan (1973), os frutos de Manihot são cápsulas com deiscência geralmente loculicida e, às vezes, septicida. Para Souza \& Lorenzi (2005), os frutos de Euphorbiaceae geralmente são cápsulas com deiscência elástica (tricoca), raramente baga, drupa ou sâmara. Nenhum destes autores, contudo, embasou suas interpretações em estudo estrutural mais detalhado. A importância de estudos anatômicos para evitar enganos ou contradições nas avaliações fica evidente quando estruturas complexas como determinados frutos são analisadas somente pela morfologia.

Para os frutos de M. utilissima, Toledo (1963) afirmou que a deiscência ocorre devido à desidratação do parênquima médio, que isola um carpelo de cada lado do eixo placentar; ao mesmo tempo, cada lóculo, devido à disposição das fibras, abre-se do ápice para a base. A autora não classificou o fruto como cápsula tricoca, embora sua descrição seja compatível com o tipo.

Fahn \& Zohary (1955) promoveram um detalhado estudo sobre estruturas pericárpicas relacionadas à deiscência de leguminosas e relataram que existe correlação entre a anatomia da valva e a deiscência, especialmente considerando a estrutura do estrato esclerenquimático. Para os autores, esta correlação, provavelmente, conduziu ao desenvolvimento de variados tipos de frutos e à deiscência ou indeiscência dos mesmos. Quando as camadas do estrato esclerenquimático estão dispostas em sentidos distintos, especialmente se antagônicos entre as valvas, o fruto normalmente é deiscente.

Comumente, para a deiscência ativa dos frutos de leguminosas, dois fatores são indispensáveis: o cruzamento de células esclerenquimáticas e/ou o cruzamento das micelas de celulose de suas paredes e a presença de um tecido de separação, que se estenda pela região da deiscência, desde a epiderme interna até a epiderme externa (Fahn \& Zohary 1955).

As características anatômicas do pericarpo das espécies estudadas de Manihot explicam o padrão do fruto no que concerne à deiscência. Desde o ovário até próximo da fase de maturação (estádio III), prevalecem células de paredes delgadas e, quando espessadas, sem lignificação. Na maturidade (estádio IV), contudo, existe grande lignificação pericárpica, mais especificamente da região interna do mesocarpo mediano e no mesocarpo interno nas duas espécies, e também da porção externa do endocarpo em $M$. tripartita.

No caso de $M$. tripartita, o estrato esclerenquimático é mais amplo e elaborado; existe uma tripla região lignificada, composta por fibroesclereídes gelatinosas de origem mesocárpica (parte mais interna do mesocarpo mediano) e endocárpica, bem como pelas braquiesclereídes com origem no mesocarpo interno. Em M. caerulescens, o mesmo não ocorre, sendo o estrato esclerenquimático duplo, formado por um estrato de fibroesclereídes gelatinosas (de origem no mesocarpo mediano) e um 
estrato de braquiesclereídes não alongadas radialmente (produzidas no mesocarpo interno).

Com relação à presença de tecido de separação, tanto em $M$. caerulescens quanto em $M$. tripartita ocorrem células parenquimáticas arredondadas e com evidentes espaços intercelulares em direção dos feixes dorsais. Já em direção aos septos, as espécies divergem mais nitidamente: nos frutos de $M$. caerulescens, existe um tecido parenquimático coeso, sem muitos espaços intercelulares, que acomoda a pressão exercida pela desidratação das células esclerenquimáticas; em $M$. tripartita, existe um tecido de separação mais laxo, separado do aerênquima do septo por algumas poucas células esclerenquimáticas, que unem a porção lignificada de um carpelo a outro. Portanto, a deiscência nesta última espécie ocorre devido à força produzida pela tripla região de esclereídes do pericarpo, que provoca a retração de cada mericarpo, rompendo-se tanto na região dorsal quanto nos septos.

Considerando os resultados obtidos, conclui-se que os frutos de $M$. caerulescens são cápsulas indeiscentes. Já os frutos de $M$. tripartita são cápsulas septi-loculicidas, uma vez que sua deiscência se dá em direção aos septos e ao feixe dorsal.

Em espécies estudadas de Phyllanthus, Webster (1956) observou que a deiscência é explosiva nas plantas herbáceas anuais, enquanto que, nas subarbustivas, a tendência é apresentar frutos carnosos com deiscência passiva e tardia ou frutos indeiscentes; nas arbóreas, são freqüentes os frutos drupáceos lenhosos. Como $M$. caerulescens e $M$. tripartita são espécies arbustivas (Durigan et al. 2004) e formam cápsulas indeiscentes e deiscentes, respectivamente, os dados aqui apresentados indicam que o proposto por Webster (1956) não pode ser estendido para outros os gêneros de Euphorbiaceae, restringindo-se a Phyllanthus.

Frutos indeiscentes têm sido relatados para algumas Euphorbiaceae por vários autores, como Barroso et al. (1999) e Souza \& Lorenzi (2005). Barroso et al. (1999), inclusive, mencionaram que existem cápsulas indeiscentes, porém não informaram em quais gêneros ou espécies foram encontrados estes frutos.

Em M. caerulescens, registrou-se que o próprio pericarpo compõe, em conjunto com as sementes, o diásporo. Este pericarpo acumula mais reserva de amido que o de $M$. tripartita, onde o diásporo é a própria semente e a dispersão é, inicialmente, autocórica; nesta espécie, a participação do pericarpo na dispersão restringe-se à exposição da semente. Em observações pessoais de campo, foram encontradas grandes formigas, alimentando-se dos frutos de M. caerulescens. Assim, a indeiscência desenvolvida nesta espécie pode representar adaptação do pericarpo à zoocoria, já que ele apresenta compostos nutritivos que podem ser explorados pelo dispersor sem causar nenhum dano à semente, que se encontra protegida pelo estrato esclerenquimático bem desenvolvido.

Agradecimentos - Ao CNPq, pela bolsa de mestrado concedida a J.H.G. de Oliveira e pela bolsa de produtividade em pesquisa de D.M.T. Oliveira; à Fapesp-Programa Biota (Proc. 00/12469-3), pelo auxílio financeiro; à Dra. Inês Cordeiro pela identificação das espécies e ao Sr. Clemente José Campos pela localização das plantas e auxílio em coletas.

\section{Referências bibliográficas}

AÑES, L.M.M., COELHO, M.F.B., ALBUQUERQUE, M.C.F \& DOMBROSKI, J.L.D. 2005. Caracterização morfológica dos frutos, das sementes e do desenvolvimento das plântulas de Jatropha elliptica Müll. Arg. (Euphorbiaceae). Revista Brasileira de Botânica 28:563-568.

APG. 2003. An update of the Angiosperm Phylogeny Group classification for the orders and families of flowering plants: APG II. Botanical Journal of the Linnean Society 141:399-436.

BARROSO, G.M., PEIXOTO, A.L., COSTA, C.G., ICHASO, C.L.F., GUIMARÃES, E.F. \& LIMA, H.C. 1991. Sistemática de Angiospermas do Brasil. Imprensa Universitária, Viçosa.

BARROSO, G.M., MORIM. M.P., PEIXOTO, A.L. \& ICHASO, C.L.F. 1999. Frutos e sementes: morfologia aplicada à sistemática de dicotiledôneas. Editora UFV, Viçosa.

BERG, R.Y. 1975. Fruit, seed, and myrmecochorous dispersal in Micrantheum (Euphorbiaceae). Norwegian Journal of Botany 22:173-194.

CUTTER, E.C. 1986. Anatomia vegetal (primeira parte): células e tecidos. $2^{\mathrm{a}}$ ed. Ed. Roca, São Paulo.

DOP, P. \& GAUTIÉ, A. 1928. Manuel de tecnique botanique. J. Lamane, Paris.

DURIGAN, G., BAITELLO, J.B., FRANCO, G.A.D.C. \& SIQUEIRA, M.F. 2004. Plantas do cerrado paulista: imagens de uma paisagem ameaçada. Páginas \& Letras Editora e Gráfica, São Paulo.

ESAU, K. 1959. Anatomía vegetal. Ediciones Omega, Barcelona.

FAHN, A. \& ZOHARY, M. 1955. On the pericarpial structure of the legumen, its evolution and relation to dehiscence. Phytomorphology 5:99-111.

FRANKLIN, G.L. 1945. Preparation of thin section of the synthetic resins and wood-resin composites, and a new macerating method for wood. Nature 155:51.

GRANER, E.A. 1942. Notas sobre florescimento e frutificação da mandioca. Bragantia 2:1-2. 
JENSEN, W.A. 1962. Botanical histochemistry: principles and practice. W.H. Freeman, San Francisco.

JOHANSEN, D.A. 1940. Plant microtechnique. McGrawHill Book, New York.

KRAUS, J.E. \& ARDUIN, M. 1997. Manual básico de métodos em morfologia vegetal. EDUR, Seropédica.

LAGÔA, A.M.M.A. \& PEREIRA, M.F.D.A. 1989. Envolvimento do tegumento no controle da germinação de sementes de Ricinus communis L. Revista de Biologia 14:213-220.

LANDES, M. 1946. Seed development in Acalypha rhomboidea and some other Euphorbiaceae. American Journal of Botany 33:562-568.

LILLELAND, O. 1930. Growth study of the apricot fruit. Proceedings of the American Society of Horticultural Sciences 27:237-245.

O'BRIEN, T.P., FEDER, N. \& MCCULLY, M.E. 1964. Polychromatic staining of plant cell walls by toluidine blue O. Protoplasma 59:368-373.

OLIVEIRA, D.M.T. \& BELTRATI, C.M. 1993. Aspectos anatômicos dos frutos e sementes em desenvolvimento de Inga fagifolia (Fabaceae: Mimosoideae). Revista Brasileira de Biologia 53:625-636

PAOLI, A.A.S., FREITAS, L. \& BARBOSA, J.M. 1995. Caracterização morfológica dos frutos, sementes e plântulas de Croton floribundus Spreng. e de Croton urucurana Baill. (Euphorbiaceae). Revista Brasileira de Sementes 17:57-68.

PIETROBOM, R.C.V. \& OLIVEIRA, D.M.T. 2004. Morfoanatomia e ontogênese do pericarpo de Schizolobium parahyba (Vell.) Blake (Fabaceae, Caesalpinioideae). Revista Brasileira de Botânica 27:767-779.

ROGERS, D.J. \& APPAN, S.G. 1973. Manihot, Manihotoides (Euphorbiaceae). Flora Neotropica 13:1-272.

ROOSMALEN, M.G.M. 1985. Fruits of the guianan flora. Institute of Systematic Botany, Utrecht University, Utrecht.

ROTH, I. 1977. Fruits of Angiosperms. Gebrüder Borntraeger, Berlin. (Handbuch der Pflanzenanatomie).

SASS, J.E. 1951. Botanical microtechnique. $2^{\text {nd }}$ ed. Iowa State University Press, Ames.
SINGH, R.P. 1954. Structure and development of seeds in Euphorbiaceae: Ricinus communis L. Phytomorphology 4:118-123.

SINGH, R.P. 1969. Structure and development of seeds in Euphorbia helioscopia. Botanical Magazine Tokyo 82:287-293.

SINGH, R.P. \& CHOPRA, S. 1970. Structure and development of seeds in Croton bonplandianum. Phytomorphology 20:83-87.

SOUZA, L.A. 1984. Anatomia do desenvolvimento do pericarpo de Lonchocarpus muehlbergianus Hassler (Leguminosae - Faboideae). Revista Unimar 6:5-19.

SOUZA, V.C. \& LORENZI, H. 2005. Botânica sistemática: guia ilustrado para identificação das famílias de Angiospermas da flora brasileira, baseado em APG II. Editora Plantarum, Nova Odessa.

TOKUOKA, T. \& TOBE, H. 1998. Ovules and seeds in Crotonoideae (Euphorbiaceae): structure and systematic implications. Botanische Jahrbücher für Systematik 120:165-186.

TOKUOKA, T. \& TOBE, H. 2002. Ovules and seeds in Euphorbioideae (Euphorbiaceae): structure and systematic implications. Journal of Plant Research 115:361-374.

TOKUOKA, T. \& TOBE, H. 2003. Ovules and seeds in Acalyphoideae (Euphorbiaceae): structure and systematic implications. Journal of Plant Research 116:355-380.

TOLEDO, A.P. 1963. Anatomia e desenvolvimento ontogenético do fruto e da semente de mandioca. Bragantia 22:521-526.

TUKEY, H.B. \& YOUNG, J.O. 1939. Histological study of the developing fruit of the sour cherry. Botanical Gazette 100:723-749.

WEBSTER, G.L. 1956. A monographic study of the West Indian species of Phyllanthus. Journal of the Arnold Arboretum 37:91-268.

WEBSTER, G.L. 1994. Synopsis of the genera and suprageneric taxa of Euphorbiaceae. Annals of the Missouri Botanical Garden 81:33-144. 